\title{
GCU
}

Glasgow Caledonian

University

University for the Common Good

\section{The impact of cognitive-communication difficulties following traumatic brain injury on the family; a qualitative, focus group study}

Grayson, Lynn; Brady, Marian C.; Togher, Leanne; Ali, Myzoon

Published in:

Brain Injury

DOI:

$10.1080 / 02699052.2020 .1849800$

Publication date:

2021

Document Version

Author accepted manuscript

Link to publication in ResearchOnline

Citation for published version (Harvard):

Grayson, L, Brady, MC, Togher, L \& Ali, M 2021, 'The impact of cognitive-communication difficulties following traumatic brain injury on the family; a qualitative, focus group study', Brain Injury, vol. 35, no. 1, pp. 15-25. https://doi.org/10.1080/02699052.2020.1849800

\section{General rights}

Copyright and moral rights for the publications made accessible in the public portal are retained by the authors and/or other copyright owners and it is a condition of accessing publications that users recognise and abide by the legal requirements associated with these rights.

Take down policy

If you believe that this document breaches copyright please view our takedown policy at https://edshare.gcu.ac.uk/id/eprint/5179 for details of how to contact us. 
The impact of cognitive-communication difficulties following traumatic brain injury on the family; a qualitative, focus group study

Lynn Grayson ${ }^{\mathrm{a}, \mathrm{b} *}$, Marian C. Brady ${ }^{\mathrm{a}}$, Myzoon Ali $^{\mathrm{a}}$ and Leanne Togher ${ }^{\mathrm{c}}$

${ }^{a}$ NMAHP Research Unit, Glasgow Caledonian University, Glasgow, Scotland, ${ }^{b}$ NHS Lanarkshire, Carluke, Scotland and ${ }^{c}$ Faculty of Medicine and Health, The University of Sydney, Australia

*lynn.grayson@gcu.ac.uk 


\title{
The impact of cognitive-communication difficulties following traumatic brain injury on the family; a focus group study
}

\begin{abstract}
Primary Objective: To identify how families experience cognitive-communication difficulties following Traumatic Brain Injury (TBI). Experiences of information, training and support for managing communication changes was also explored. Research Design: Qualitative focus group methodology using thematic analysis. Method Fifteen family members of individuals with cognitive-communication difficulties following severe TBI participated in the study; 4 parents, 6 spouses, 3 siblings and 2 offspring. The majority of participants were female $(80 \%, n=12)$, with a mean age of 51 (range 19-71). Four focus groups were held with family members at 0 12 months, 12-36 months and 36+ months post-injury. The data was transcribed verbatim and analysed using NVIVO 12. Results: Cognitive-communication difficulties were found to impact upon family functioning and psychological wellbeing for several years post injury. Changes to social cognition, insight and the "filter switch" of the person following TBI were key areas of distress. Participants highlighted the need for information about communication changes to be provided at several time points post injury. The need for peer support from other families with experience of cognitive-communication difficulties was also identified. Conclusion: Cognitivecommunication difficulties impact upon family functioning for many years following injury with families continuing to have support needs for communication well beyond the acute rehabilitation stage.
\end{abstract}

Keywords: traumatic brain injury, cognitive-communication difficulties, family experience, focus groups, service provision

\section{Introduction:}

Traumatic Brain Injury (TBI) is a significant cause of long-term disability with an estimated 500,000 people, approximately one family in 300, affected in the United Kingdom (1). Families often take on the responsibility of providing long term support to the person following moderate-severe TBI, resulting in high levels of caregiver burden, psychological distress and changes to family functioning (2-12). In addition to the complex neurobehavioural effects associated with moderate-severe TBI; impaired awareness, behavioural rigidity, impulsivity, irritability, anger, changes to memory and information processing, families frequently report changes to communication as a key area of distress (13-16). 
Cognitive-communication difficulties (CCD) resulting from disrupted cognitive processes (e.g. attention, memory, executive function) rather than specific language disorder is the most prevalent communication difficulty following TBI (17-19). CCDs are wide ranging and can include negative changes to comprehension, word finding, discourse and social communication (20-23). CCD significantly impacts upon the person following TBI's ability to participate socially and maintain relationships $(16,24)$. More longitudinal investigation into the course of CCD is required, however, as there are currently no studies which investigate CCD following TBI longer than three years post injury (25). Recent studies have started to address this issue by measuring how CCD changes and impacts upon psychosocial functioning over time $(26,27)$. Growing awareness of the need for interventions that specifically address social cognition changes following TBI (impairments in theory of mind, perspective taking, cognitive empathy and emotional perception) has also resulted in number of recent papers in this area (28-32).

Despite decades of research demonstrating the profound impact moderate-severe TBI has on family functioning, families consistently report that services are inadequate and fail to meet their needs (33-38). This has led to a number of qualitative studies investigating the lived experience of family members in an attempt to help services better understand what support is required. One study investigating the narratives of family members in their first year following TBI provided key insights into how families gradually develop an awareness of the long-term effects of brain injury (39). Participants initially focused upon continuity of the person following TBI’s personality traits before experiencing narrative disruption as changes became more evident. Some families required support to move to the final stage of reconstructing new narratives, particularly as differences in perception between family members could lead to narrative malalignment. Similar themes of continuity-discontinuity and coping-not coping were also evident in a study investigating the lived experience of family members, several years following TBI (40). Support to develop coping strategies was viewed positively by participants and was identified as required at several time points following injury, not just in the early stages.

Family experience of severe acquired brain injury, specifically in relation to services and support systems, was explored in a recent study involving the semi-structured interviews of family members 2-28 years following the event (41). Themes emerged relating to "the allencompassing challenge”, "loss and grief”, with family members experiencing an "ever present, unavoidable duty”. Participants also experienced poor communication between 
services, lack of specialist knowledge in the community and a failure of professionals to take on board the families' perspective. These findings echo the results of previous studies in a number of countries which have identified TBI services as unorganised, lacking in specialist TBI education and unresponsive to the long-term continuum of care required by both the person following TBI and their relatives (42-46).

The need for interventions that provide support, education and skill building to the families of individuals following TBI is clearly recognised although more empirical research is required to establish their efficacy. A recent systematic review identified that many of the TBI specific family intervention studies were limited by small sample sizes, bias on randomisation techniques and reduced fidelity (47). The effect of individual programme components, e.g., TBI education, was also difficult to discern (48) although positive findings have recently emerged for peer support, problem solving, manualised group intervention programmes and couples' therapy (49-57). A number of studies have also explored whether the service needs of family members may differ depending upon their relationship to the person following TBI (56-59). Although findings have been mixed, a recent qualitative study found that partners perceived a number of subthemes differently to parents (60). For example, partners expressed more intense frustration about the responsibility of having to shoulder the caregiver burden alone, whereas parents talked about a return to a more supportive parenting role with fear for the future when they could no longer provide this care.

Involving family members in communication partner training (CPT) results in improved communication outcomes for the person following TBI and is recommended as best practice for Speech and Language Pathologists (SLP) $(61,62,63)$. Family caregivers report less stress at social events and improved confidence in supporting the person following TBI in conversations following CPT interventions (64). Few studies have explored how family members experience and manage the consequences of CCD over the longer term, however, and a recent survey identified that families experience high levels of unmet need for CCD over this trajectory (65).

The aim of this study was therefore to develop a greater understanding of the impact CCD have on family members over time and explore how services can optimise the information, training and support they provide to families with regard to CCD.

\section{Research Questions:}


- How do cognitive-communication changes following TBI affect families?

- Does family experience of CCD following TBI change over time?

- How can services best support the families of individuals with CCD following TBI?

\section{Method:}

\section{Design:}

A focus group methodology was employed as it enabled us to capture a range of experiences and views about CCD from the perspective of family members. This project was approved by NHS West midlands- Black Country research ethics committee (reference number 19/WM/0072; IRAS project number 260091).

\section{Participants:}

Individuals eligible for inclusion were the adult family members (over 18) of people with a diagnosis of CCD documented by a Speech and Language Pathologist (SLP) in their medical notes (defined as difficulty paying attention to conversations, staying on topic, remembering information, responding accurately, understanding jokes and/or following directions) as a result of sustaining a severe Traumatic Brain Injury (defined as a brain injury caused by road traffic accident, assault or fall with a score on the Glasgow Coma Scale (GCS) of 8 or less and/or a period of Post Traumatic Amnesia (PTA) of more than 24 h) (66). Family members of individuals who were less than three months post injury or still in post-traumatic amnesia PTA (defined as the period of disorientation as coma) were not eligible for inclusion.

\section{Procedure:}

The lead researcher (LG) identified eligible participants from the NHS Lanarkshire's Community Brain Injury Team’s (CBIT) current caseload and from a database of previous CBIT clients who had consented to being contacted about future research. All eligible participants were contacted by phone and then sent out a detailed, typed participant information sheet which emphasised that participation in the focus group was voluntary. Options for suitable times and locations were provided and all participants completed a written consent form prior to participating in the focus group.

Four focus groups took place. Participants were grouped in relation to time since injury (0-12 months, 12-36 months and 36+ months) to ensure relatable experience to the 
other group members and to minimise distress. Two focus groups for $36+$ months were held to accommodate for the geographically diverse location of these participants.

Each focus group lasted between 1 and 1.5 hours and were led by two facilitators (LG and an experienced CBIT therapist, unconnected to the project, who observed and took field notes). LG is a speech pathologist working in CBIT with 23 years of clinical experience in adult neurogenic communication disorders. She holds an honours degree in speech pathology. A focus group topic guide containing information on group set up and open-ended questions relating to the participants' experience of CCD following TBI and the information, training and support that would be useful to participants was used to ensure parity across the three groups (see appendix 1).These questions were piloted on three family members, three brain injury survivors and three therapists currently working with CBIT. This was to ensure the questions were relevant and sensitively worded in addition to ascertaining the time required for completion of all questions on the guide.

Of the fifteen participants that took part in the focus groups; $80 \%(n=12)$ were female, with a mean age of 51 (range 19-71) and related to the person following TBI in a range of ways; parent $27 \%(n=4)$, spouse $40 \%(n=6)$, sibling $20 \%(n=3)$ and child $13 \%(n=2)$. Parents and spouses were equally distributed across all time bands with siblings and offspring represented in the 18-36m and 36m+ focus groups. The majority of TBI survivors being described were male ( $87 \% n=13)$ with a mean age of 49 (range 24-63). Mean time since the brain injury event was four years six months (range 5 months- 10 years 8 months). All participants were British and resided within Lanarkshire, Scotland.

\section{Analysis:}

The focus groups were digitally recorded and the audio recordings transcribed verbatim (LG). Each participant was provided with an anonymous code to de-identify the transcripts and a thorough six stage thematic analysis (67) was carried out using a combination of manual and computer assisted methods (NVivo 12). This involved reading and re-reading the transcripts to get an overall sense of the data prior to grouping the responses to each question together and 'coding' the main ideas. Coding involved working methodically through each of the four transcripts to select comments which were put into containers called 'nodes'(LG). New nodes were added as we progressed through the text and this resulted in a list of open codes (LG). The different codes were then sorted into potential themes and LG worked with the other 
authors to identify overarching themes and sub-themes. The research team then worked closely together to review and refine the themes and identify suitable extracts for each theme. This enabled the themes to be organised into a coherent and internally consistent account, with an accompanying narrative.

\section{Rigor:}

A number of measures to protect the study from bias were employed. The study was conducted in reference to the consolidated criteria for reporting qualitative research COREQ (68). The first author followed the focus group guide, including only the questions (which had been piloted on service users) stated within this guide. Member checking was conducted throughout each focus group by facilitators summarising the information provided by participants to confirm whether their message had been understood correctly. Second research team members (MA, LT and MCB) and an experienced CBIT therapist unconnected to the study were involved in the review, analysis, coding and write up to ensure agreement of the themes/codes selected. These reviewers had access to the anonymous transcriptions but not participants’ personal details.

\section{Results:}

Thematic analysis resulted in 60 codes which were organized into three themes, nine categories and thirty-five sub-categories (refer to Table 1).

Table 1: Themes, Categories and Sub-categories

"Family experience of CCD," "impact of CCD on the family," and "how services can optimise support for the family in relation to CCD," were the three superordinate themes identified.

\section{Theme one- Experience of CCD:}

Participants from all four focus groups highlighted that changes to the person following TBI's ability to recognise the emotional needs of others and respond flexibly to feedback during conversations were key areas of distress. Changes to the person following TBI's "filter switch" e.g. knowing what is appropriate to say to different people, and lack of awareness of CCD also emerged as strong themes regardless of the time since injury, age or relationship to the person with the injury. Statements about the impact of memory, word finding difficulties 
and initiation on communication were present but in fewer numbers and not consistently across all groups. Table 2 provides a summary of how families experience CCD with illustrative quotes:

Table 2: Family Experience of Cognitive-Communication Difficulties

\section{Strategies:}

Participants from all focus groups identified a number of strategies that they were using with their loved one to support CCD. Table 3 provides a summary of the strategies identified by families with illustrative quotes:

Table 3: Family Strategies for supporting Cognitive-Communication Difficulties

\section{Theme 2-Impact:}

Participants discussed feelings of anxiety, frustration and exhaustion in relation to needing to be on duty and supporting their loved one with CCD all of the time. Feelings of loneliness and isolation were exacerbated by the hidden nature of CCD which affected the perception of not only strangers but also the participants' wider network of family and friends. Differences of opinion between family members about the nature of CCD lead to further feelings of anxiety, increased responsibility and isolation. Table 4 provides a summary of the emotional impact of CCD experienced by family members:

Table 4: Emotional impact of Cognitive- Communication Difficulties on Family Members

\section{Relationships:}

Participants expressed sadness at how CCDs had impacted upon the role of the individual following TBI within the family. This included reduced responsibility and participation in family activities. A key theme to emerge was how CCD had impacted upon positive patterns of collaboration between the person following TBI and their relatives. This had a significant impact on family cohesion and the feeling of "being in it together". Participants identified that some rehabilitation approaches such as involving the family member in sessions to improve insight and setting individual goals with the person following TBI could inadvertently impact upon collaboration further. A number of parents and siblings also commented upon how they felt the spouses within the group had experienced more of an impact. Table 5 provides a summary of the impact of CCD on Relationships: 
Table 5: Impact of Cognitive-Communication Difficulties on Relationships

\section{Social Participation:}

Participants discussed how the person following TBI's CCD had resulted in reduced social contacts, reluctance to attend social events and increased need for support. This theme became more prominent in focus groups two to four (12-36months and 36+ months). Table 6 provides examples of how CCD has impacted upon Social Participation:

Table 6: Impact of Cognitive-Communication Difficulties on Social Participation

\section{Theme 3- How services can support family members with CCD:}

\section{Information:}

Participants were keen to have information about how CCD difficulties correlate with specific areas of damage within the brain and spoke about how their awareness of CCD had developed gradually over time. This was in contrast to physical changes and more obvious cognitive difficulties, such as memory, which participants reported were easier to identify. The need for verbal and written information about CCD to be provided at several points over time to allow families to gradually adjust and gain insight into these more subtle changes therefore arose as a theme common to all focus groups.

Lack of insight into CCD impacted upon the ability of family members to talk freely with the SLP about their concerns when the person following TBI was present. Participants felt this could be alleviated by family members being offered one appointment on their own as this would allow them to provide information and ask questions in an unguarded way. Table 7 provides a summary of the key themes that emerged for information:

Table 7: Optimizing information about Cognitive-Communication Difficulties for families

\section{Communication Partner Training:}

Family perception of communication partner training was less unified. Some participants felt training would be empowering as they would feel more competent and involved in supporting the person following TBI whereas others were concerned that training might 
further affect their confidence and emotional wellbeing. Table 8 provides participant opinions regarding training:

Table 8: Family perception of the need for Communication Partner Training

\section{Support:}

Family members from all time points post injury spoke about the lack of opportunity to talk about the impact of CCD with others. This arose from the hidden nature of the disability, within family differences in opinion and feelings of guilt about saying something negative about their loved one to other people. The need for peer support emerged as a key theme during discussions although the families in this study did not feel that third sector services were currently meeting this need locally. This was due to the lack of local carers groups and the wide mix of abilities at general meetings which precluded specific conversations about CCD. Table 9 summarizes the main themes to arise regarding family support for CCD:

Table 9: Optimizing Family Support for Cognitive-communication difficulties

\section{Discussion:}

Our findings show that CCD difficulties following severe TBI continue to impact upon the lives of families for several years post injury. Participants in the 36 months + focus groups continued to express concern about the same CCD changes that were identified by participants in the 0-12 months and 12-36 months groups. This lends support to the findings that CCD difficulties persist over time $(15,16,24,27,65)$ and reinforces the need for further longitudinal research and clinical support over this trajectory (25).

The impact of social cognition changes on everyday communication was evident as a significant theme in all focus groups, across all age groups and relationship types. This reinforces the legitimacy of recent interest in this area, particularly the need to develop interventions which educate and support the whole family (28-31). Lack of insight into communication changes, difficulty accepting feedback and reduced "filter switch" were also identified as concerns by family members more frequently than discourse changes such as impoverished speech, verbosity and the impact of memory on communication. This may indicate that the families in this study were less concerned about discourse changes following TBI or it could simply reflect that current SLP services were better at meeting the needs of 
families in these areas. Further investigation into family perception of their needs for CCD is therefore required to enable SLP's to tailor the content of interventions and family education for CCD accordingly.

The emotions and experiences of participants in this study drew many similarities to the findings of other qualitative studies exploring the impact of severe brain injury on the family $(40,41,60)$. The themes of "being the bad guy" and "never-ending responsibility", for example, reflect not only managing CCD but also relate to the effects of severe TBI in general. A number of participants also commented specifically on how the support needs of spouses/ partners may be different to other family members due to spouses feeling more isolated/alone. This observation has been identified in some other studies (58-60) and merits further investigation. Differences in opinion within families about the nature of CCD led to increased distress and reduced family cohesion. This echoes the findings of the study exploring family narratives (39) and reinforces the need for services to consider whole family education/ support.

One interesting theme to emerge from this study was that family members experienced significant disruption in their ability to work together "on the same team" as the person following TBI. Communication situations involving negotiation and joint decision making were much more difficult and certain rehabilitation practices could inadvertently diminish rather than promote family cohesion. Joint interventions which encourage the person following TBI and their family to develop a more congruent narrative about recovery following TBI and collaborative family goal setting is therefore a priority.

Families discussed how CCD directly impacted upon their loved ones' ability to socialise and sustain key roles within relationships. This reflects the finding of several studies exploring the impact of CCD on participation $(16,17,24,27)$ and emphasises the need for social participation/maintenance of relationship roles to be central to rehabilitation goal setting and long- term service planning for both the person following TBI and their families.

Family opinion regarding the need for communication partner training for CCD following TBI was divided with a number of participants unsure whether formal training approaches would suit them. This adds to the findings from a previous study where a percentage of family members reported feeling uncomfortable by CPT in the initial stages (64). A key theme to emerge from all focus groups was that family members really struggle with their loved one being unable to accept feedback. As a central aim of CPT is for the 
person following TBI and family member to work collaboratively together within conversations, SLP's have a duty to alleviate the concerns of family members regarding CPT in order for improved family interactions and cohesion longer term. Family members in the focus groups were able to identify a number of CCD strategies they were already using with their loved one and felt comfortable discussing these with other family members. Solution focused group therapy, which empowers the person to identify solutions and set their own goals in a supportive, facilitated group, has been used with the caregivers of people following stroke (69). This could be considered as an alternative approach to use with family members who are reluctant for more formal CPT.

The need for peer support from other families with direct experience of CCD following TBI was a strong theme to emerge from this study and reinforces positive research findings from peer mentoring programmes $(49,50)$. Relatives also identified the need for 1:1 time to discuss the impact of CCD with the SLP and for information about CCD to be provided at several points over time. This would enable families to feel that their views were being listened to and that services were becoming more responsive to their long-term needs for CCD (42-46).

\section{Strengths and Limitations:}

This study enriches our knowledge of the specific CCD's that families find distressing and how they can impact upon family functioning over the longer term. The participants in the study also shared important insights into their experience of services for communication changes following TBI and how information, training and support for managing CCD could be improved. The study benefitted from gathering information from relatives of different ages, relationship types and time since the TBI event but the results cannot be taken to reflect the experiences of all families following TBI due to the following limitations; the information provided by participants was taken at a single point in time and is likely to have been influenced by their mood at the time of the group, ability to recall rehabilitation experiences and the dynamics within the group. No siblings or offspring were represented within the 0$12 \mathrm{~m}$ focus group and although rigorous steps were taken to overcome researcher bias the lead researcher's (LG) dual role as CBIT clinician and researcher may have resulted in participants feeling uncomfortable about sharing more negative rehabilitation experiences. The study involved a relatively small convenience sample of participants recruited from a single clinical location. The experiences of the participants in this study may therefore not 
reflect the experiences of caregivers from other geographical areas who have a different socio-cultural background. There was a gender bias towards female caregivers describing their experiences of males with CCD following TBI. The results may therefore not reflect the CCD difficulties experienced by females following TBI or the caregiving experience of male caregivers.

\section{Research Implications:}

This study highlights the need for longer term research into the effectiveness of interventions for CCD later post injury in addition to investigating the impact of training and information provision for families affected by CCD following TBI. Further investigation into effective interventions for social cognition e.g. developing the person following TBI’s ability to recognise and react to the emotional needs of others within conversations is required. It would also be useful to explore whether receiving intervention for social cognition and collaborative communication in the first 0-12 months would impact upon the communication needs of the person following TBI and their families in the longer term. Future studies should consider how CCD is experienced in relation to the sex of the person following TBI, and their caregiver, and in the context of different relationships, socio-cultural and geographical backgrounds to determine how family experience of support services can be optimised.

\section{Clinical implications:}

This study provides SLP's with important insights into the areas of CCD causing concern for families and how these persist over time. Families require information about how social cognition changes may affect everyday communication in addition to how CCD may impact upon social participation and relationship roles over the longer term. The timing of CCD information and advice needs to fit with the evolving understanding of the family member and should be considered at several time points in the recovery journey. Family members need to talk about the impact of CCD and would benefit from 1:1 time with an SLP in addition to peer support from other family members who have had a similar experience of CCD. A key role for SLP's is the development of collaborative working and positive interactions between family members and the person following TBI. This can be provided through CPT, promoting joint narratives about rehabilitation and setting whole family goals which foster the maintenance of important relationship roles for the person following TBI. Careful consideration of how to present the idea of CPT to families may be required and 
some families may prefer a solution focused group therapy approach which acknowledges the power of families to develop and share useful strategies with each other.

\section{Conclusion:}

We aimed to gain a better understanding of the experiences of family members with regard CCD following TBI. This research has highlighted that CCD difficulties continue to impact upon family functioning and social participation for many years following injury with families continuing to have support needs for CCD well beyond the acute rehabilitation stage. The family members in this study provided important insights into how changes to social cognition, insight, impulsivity and rigid thinking directly impact upon everyday communication with the person following TBI and the emotional wellbeing of the family member. Families require information about CCD at various stages throughout their journey and the opportunity to talk about CCD difficulties with peers who have had a similar experience. Working collaboratively with families and the person with TBI to maintain participation in key relationship roles and social activities should be central to any intervention.

\section{Acknowledgments}

The authors would like to acknowledge and thank the family members who participated in the focus groups which informed this research.

Ethical Approval

NHS ethical approval was sought via the Integrated Research Application System (IRAS project number 260091) and granted by NHS West Midlands- Black Country research ethics committee (reference number 19/WM/0072).

Declaration of Interests

The authors report no conflicts of interest. The authors alone are responsible for the content and writing of the paper.

Funding

This work is part of an MPhil qualification, undertaken by the first author, which was funded by NHS Lanarkshire.

Data Availability Statement

The data that support the findings of this study are available on request from the corresponding author, [LG]. The data are not publicly available due to their containing information that could compromise the privacy of research participants. 
L. GRAYSON ET AL

ORCHID

Leanne Togher https://orcid.org/0000-0002-4518-6748

Marian Brady http://orcid.org/0000-0002-4589-7021

Myzoon Ali https://orcid.org/0000-0001-5899-2485

\section{References:}

1. King NS, Tyerman A. Neuropsychological presentation and treatment of head injury and traumatic brain damage. In: Halligan PW, Kischka U, Marshall JC, editors. Handbook of clinical neuropsychology. Oxford (UK): Oxford University Press; 2003.

2. Marsh NV, Kersel DA, Havill JH, Sleigh JW. Caregiver burden at 1 year following severe traumatic brain injury. Brain Inj, 1998; 12(12):1045-1059. doi:10.1080/026990598121954

3. Ponsford J, Schonberger M. Family functioning and emotional state two and five years after traumatic brain injury. Journal of the International Neuropsychological society, England, 2010; 16(2):306-317. doi:10.1017/s1355617709991342

4. Brooks N, Campsie, L, Symington, C, Beattie, A, McKinlay, W. The five year outcome of severe blunt head injury: a relative's view. Journal of Neurology, Neurosurgery \& Psychiatry, 1986; 49(7):764-770. doi:10.1136/jnnp.49.7.764

5. Douglas JM, Spella FJ. Correlates of depression in adults with severe traumatic brain injury and their carers. Brain Inj, England, 2000; 14(1):71-88. ISSN 0269-9052 https://doi.org/10.1080/026990500120943

6. Thomsen IV. Late outcome of very severe blunt head trauma: a 10-15 year second follow-up. Journal of neurology, neurosurgery, and psychiatry, England, 1984; 47(3):260-268. ISSN 0022-3050. https://doi.org/10.1136/jnnp.47.3.260

7. Rotondi AJ, Sinkule J, Balzer K, Harris J, Moldovan R. A qualitative needs assessment of persons who have experienced traumatic brain injury and their primary family caregivers. J Head Trauma Rehabil, 2007; 22(1):14-25.

8. Gan C, Campbell KA, Gemeinhardt M, McFadden GT. Predictors of family system functioning after brain injury. Brain Inj, 2006;20(6):587-600.

doi:10.1080/02699050600743725 
9. Man DWK, Family caregivers' reactions and coping for persons with brain injury. Brain Inj, 2002;16(12):1025-1037. ISSN 0269-9052. https://doi.org/10.1080/0269905021000010087

10. Ramkumar NA, Elliot TR. Family caregiving of persons following neurotrauma: issues in research, service and policy. NeuroRehabilitation, 2010;27(1):105-12. ISSN 1878-6448. https://doi.org/10.3233/nre-2010-0585

11. Minnes P, Graffi S, Nolte ML, Carlson P, Harrick L, Coping and stress in Canadian family caregivers of persons with traumatic brain injuries. Brain Inj, 2002;14(8):737748. doi:10.1080/026990500413768

12. Kolakowsky-Hayner SA, Kinshore R, Caregiver functioning after traumatic injury. Neurorehabilitation, 1999; 13:27-33.

13. Vangel SJ, Rapport LJ, Hanks RA. Effects of family and caregiver psychosocial functioning on outcomes in persons with traumatic brain injury. J Head Trauma Rehabil, 2011;26(1):20-9. ISSN 1550-509X. doi:10.1097/htr.0b013e318204a70d

14. Winstanley J, Simpson G, Tate R, Myles B. Early Indicators and Contributors to Psychological Distress in Relatives During Rehabilitation Following Severe Traumatic Brain Injury: Findings From the Brain Injury Outcomes Study. Journal of Head Trauma Rehabilitation, 2006;21(6):453-466. doi:10.1097/00001199200611000-00001

15. Anderson MI, Parmenter TR, Mok, M. The relationship between neurobehavioural problems of severe traumatic brain injury (TBI), family functioning and the psychological well-being of the spouse/caregiver: path model analysis. Brain Inj, 2002;16(9):743-757. ISSN 0269-9052. https://doi.org/10.1080/02699050210128906

16. Struchen AM, Pappadis RM, Sander MA, Burrows SC, Myszka AK. Examining the Contribution of Social Communication Abilities and Affective/Behavioral Functioning to Social Integration Outcomes for Adults With Traumatic Brain Injury. Journal of Head Trauma Rehabilitation,2011;26(1):30-42. doi:10.1097/HTR.0b013e3182048f7c

17. Marini A, Zettin M, Galetto V. Cognitive correlates of narrative impairment in moderate traumatic brain injury. Neuropsychologia, England, 2014; 64:282-288, ISSN 0028-3932. https://doi.org/10.1016/j.neuropsychologia.2014.09.042

18. Coelho CA. Management of discourse deficits following traumatic brain injury: progress, caveats, and needs. Semin Speech Lang, May 2007;28(2):122-35 ISSN 0734-0478. https://doi.org/10.1055/s-2007-970570 
19. Rispoli MJ, Machalicek W, Lang R. Communication interventions for individuals with acquired brain injury. Dev Neurorehabil, 2010;13(2):141-51. ISSN 1751-8431. https://doi.org/10.3109/17518420903468464

20. Bond F, Godfrey HPD. Conversation with traumatically brain injured individuals: a controlled study of behavioural changes and their impact. Brain Inj, England, 1997;11(5):319-330. https://doi.org/10.1080/026990597123476

21. McDonald S,Togher L, Code, C. Social and communication disorders following traumatic brain injury. 2ed. London (NY): Psychology Press, Taylor \& Francis Group, 2014. ISBN 1848721358;1848721293;9781848721357;9781848721296;. https://doi.org/10.4324/9780203557198

22. Snow P, Douglas.J, Ponsford J. Conversational assessment following traumatic brain injury: a comparison across two control groups. Brain Inj, England, 1997;11(6):409429. ISSN 0269-9052 U6 - 080_026990597123403 doi./10.1080/026990597123403

23. Spence SE, Godfrey HP, Knight RG, Bishara SN. First impressions count: a controlled investigation of social skill following closed head injury. The British journal of clinical psychology.1993;32(3):309-318. doi:10.1111/j.20448260.1993.tb01061.x

24. Douglas JM, Conceptualizing self and maintaining social connection following severe traumatic brain injury. Brain Inj, England,2013;27(1):60-74. ISSN 0269-9052. https://doi.org/10.3109/02699052.2012.722254

25. Elbourn E, Togher L, Kenny B, Power, E. Strengthening the quality of longitudinal research into cognitive-communication recovery after traumatic brain injury: A systematic review. International journal of speech-language pathology, 2017;19(1):116. doi:10.1080/17549507.2016.1193896

26. Elbourn E, Kenny B, Power E, Honan C, McDonald S, Tate R., Holland A, MacWhinney B, Togher L. Discourse recovery after severe traumatic brain injury: exploring the first year. Brain Inj, 2019;33(2):143-159. doi:10.1080/02699052.2018.1539246

27. Tran S, Kenny B, Power E, Tate R., McDonald S, Heard R, Togher, L. Cognitivecommunication and psychosocial functioning 12 months after severe traumatic brain injury. Brain Inj, 2018;32(13-14):1700-1711.doi:10.1080/02699052.2018.1537006

28. Wearne T, Osborne-Crowley K, Rosenberg H, Dethier M, McDonald S. Emotion recognition depends on subjective emotional experience and not on facial 
expressivity: evidence from traumatic brain injury. Brain Inj, 2019;33(1):12-22. doi:10.1080/02699052.2018.1531300

29. Cassel A, McDonald S, Kelly M, Togher L. Learning from the minds of others: A review of social cognition treatments and their relevance to traumatic brain injury. Neuropsychological Rehabilitation, 2019;29(1):22-55.

https://doi.org/10.1080/09602011.2016.1257435

30. Saint-Jean M, Allain P, Besnard JA. Asociiocognitive approach to social problem solving in patients with traumatic brain injury: a pilot study. Brain Inj, 2019;33(1):4047. https://doi.org/10.1080/02699052.2018.1531306

31. Allain P, Togher L, Azouvi P. Social Cognition and Traumatic Brain Injury: current knowledge. Brain Inj, 2019;33(1):1-3. https://doi.org/10.1080/02699052.2018.1533143

32. Witol AD, Sander AM, Kreutzer JS. A longitudinal analysis of family needs following traumatic brain injury. NeuroRehabilitation, 1996;7(3):175-87. ISSN 10538135. https://doi.org/10.1016/1053-8135(96)00190-4

33. Serio CD, Kreutzer JS, Witol AD. Family needs after traumatic brain injury: a factor analytic study of the Family Needs Questionnaire. Brain Inj, 1997;11(1):1-9. ISSN 0269-9052. https://doi.org/10.1080/026990597123764

34. Moules S, Chandler BJ. A study of the health and social needs of carers of traumatically brain injured individuals served by one community rehabilitation team. Brain Inj, 1999;13(12):983-93. ISSN 0269-9052. https://doi.org/10.1080/026990599120990

35. Kolakowsky-Hayner SA, Miner KD, Kreutzer JS. Long-term life quality and family needs after traumatic brain injury. J Head Trauma Rehabil, 2001;16(4):374-85. ISSN 0885-9701. https://doi.org/10.1097/00001199-200108000-00007

36. Stebbins P, Leung P. Changing family needs after brain injury. Journal of Rehabilitation, 1998;64(4):15-22.

37. O’Callaghan AM, McAllister M, Wilson L. Experiences of care: perspectives of carers of adults with traumatic brain injury. Int J Speech Lang Pathol, 2011;13(3):218-26. ISSN 1754-9515. https://doi.org/10.3109/17549507.2011.549240

38. Dillahunt-Aspillaga C, Jorgensen-Smith T, Ehlke S, Sosinski M., Monroe D, Thor J. Traumatic brain injury: unmet support needs of caregivers and families in Florida. PLoS One, 2013;8(12):e82896. doi:10.1371/journal.pone.0082896 
39. Whiffin CJ, Ellis-Hill C, Bailey C, Jarrett N, Hutchinson PJ. We are not the same people we used to be: An exploration of family biographical narratives and identity change following traumatic brain injury. Neuropsychological rehabilitation, 2017;117. doi:10.1080/09602011.2017.1387577

40. Townshend J, Norman A. The Secondary Impact of Traumatic Brain Injury: An Interpretative Phenomenological Analysis of the Experiences of Family and Friends. The Family Journal, Los Angeles, CA, 2018;26(1):77-85. ISSN 1066-4807. https://doi.org/10.1177/1066480717752905

41. Holloway M, Orr D, Clark-Wilson J. Experiences of challenges and support among family members of people with acquired brain injury: a qualitative study in the UK. Brain inj England 2019;33(4):401-411. https://doi.org/10.1080/02699052.2019.1566967

42. Leith KH, Phillips L, Sample PL. Exploring the service needs and experiences of persons with TBI and their families: The South Carolina experience. Brain Inj, 2004;18(12):1191-1208. https://doi.org/10.1080/02699050410001719943

43. Eliacin J, Fortney S, Rattray NA, Kean J. Access to health srvices for moderate to severe TBI in Indiana: patient and caregiver perspectives. Brain Inj 2018;32(12):1510-1517. https://doi.org/10.1080/02699052.2018.1499964

44. Lefebvre H, Levert MJ. The close relatives of people who have had a traumatic brain injury and their special needs. Brain Inj, 2012;26(9):1084-1097. https://doi.org/10.1080/02699052.2018.1499964

45. Mosconi P, Taricco M, Bergamini M, Fazzi LB, Colombo C, Patrucco V, Corte M, Giobe V, Magnarella MR, Sallemi G et al. Family Burden after Severe Brain Injury: The Italian Experience with Families and Volunteer Associations. The Patient: Patient-Centered Outcomes Research, 2011;4(1):55-65. doi:10.2165/11535550000000000-00000

46. Mbakile-Mahlanza L, Manderson L, Downing M, Ponsford J. Family caregiving of individuals with traumatic brain injury in Botswana. Disability and Rehabilitation, 2017;39(6):559-567. https://doi.org/10.3109/09638288.2016.1152605

47. Kreitzer N, Kurowski BG, Bakas T. Systematic Review of Caregiver and Dyad Interventions after Adult Traumatic Brain Injury. Archives of Physical Medicine and Rehabilitation, 2018;99(11):2342-2354. https://doi.org/10.1016/j.apmr.2018.04.016 
48. Hart T. Traumatic brain injury education for adult patients and families: a scoping review, Brain Inj, 2018;32(11):1295-1306, 2018 https://doi.org/10.1080/02699052.2018.1493226

49. Hanks RA, Rapport LJ, Wertheimer J, Koviak C. Randomized controlled trial of peer mentoring for individuals with traumatic brain injury and their significant others. Archives of physical medicine and rehabilitation, 2012;93(8):1297. https://doi.org/10.1016/j.apmr.2012.04.027

50. Bellon M, Sando S, Crocker R, Farnden J, Duras M. Information, connection and giving back: peer support outcomes for families following acquired brain injury in South Australia. Health \& Social Care in the Community, 2017;25(1):204-214. doi:10.1111/hsc.12294

51. Powell JM, Fraser R, Brockway JA, Temkin N, Bell KR. A Telehealth Approach to Caregiver Self-Management Following Traumatic Brain Injury: A Randomized Controlled Trial. The Journal of head trauma rehabilitation, 2016;31(3):180-190. doi:10.1097/HTR.0000000000000167

52. Rivera PA, Elliot JR, Berry TW, Grant JS. Problem-solving training for family caregivers of persons with traumatic brain injuries: a randomized controlled trial. Archives of physical medicine and rehabilitation, 2008;89(5):931, https://doi.org/10.1016/j.apmr.2007.12.032

53. Bell KR, Brockway JA, Hart T, Whyte J, Sherer M, Fraser RT, Temkin NR, Dikmen SS. Scheduled telephone intervention for traumatic brain injury: a multicenter randomized controlled trial. Archives of physical medicine and rehabilitation, 2011; 92(10):1552.

54. Niemeier JP, Kreutzer JS, Marwitz JP, Sima AP, Godwin EE. Randomized Controlled Pilot Study of a Manualized Intervention for Caregivers of Patients With Traumatic Brain Injury in Inpatient Rehabilitation. Archives of Physical Medicine and Rehabilitation, 2019;100(4):S65-S75. https://doi.org/10.1016/j.apmr.2018.07.422

55. Kreutzer JS, Marwitz JP, Sima AP, Godwin EE. Efficacy of the Brain Injury Family Intervention: Impact on Family Members. J Head Trauma Rehabil, 2015;30(4):249260. https://doi.org/10.1097/HTR.0000000000000144

56. Livingston MG, Brooks DN, Bond MR. Three months after severe head injury: psychiatric and social impact on relatives. Journal of Neurology, Neurosurgery \& Psychiatry,1985;48(9):870-875. https://doi.org/10.1136/jnnp.48.9.870 
57. Perlesz A, Kinsella G, Crowe S. Psychological distress and family satisfaction following traumatic brain injury: injured individuals and their primary, secondary, and tertiary carers. The Journal of head trauma rehabilitation, 2000;15(3):909-929. https://doi.org/10.1097/00001199-200006000-00005

58. Ponsford J, Olver J, Ponsford M, Nelms R. Long-term adjustment of families following traumatic brain injury where comprehensive rehabilitation has been provided. Brain Injury, 2003;17(6):453-468. https://doi.org/10.1080/0269905031000070143

59. Verhaeghe S, Defloor T, Grypdonck M. Stress and coping among families of patients with traumatic brain injury: a review of the literature. Journal of Clinical Nursing, 2005;14(8):1004-1012.https://doi.org/10.1111/j.1365-2702.2005.01126.x

60. Kratz AL, Sander AM, Brickell TA, Lange RT, Carlozzi NE. Traumatic brain injury caregivers: A qualitative analysis of spouse and parent perspectives on quality of life. Neuropsychol Rehabil, 2017;27(1):16-37. https://doi.org/10.1080/09602011.2015.1051056

61. Togher SL, Wiseman-Hakes SC, Douglas SJ, Stergiou-Kita SM, Ponsford SJ, Teasell, SR, Bayley SM and Turkstra SL. 'INCOG Recommendations for Management of Cognition Following Traumatic Brain Injury, Part IV: Cognitive Communication', Journal of Head Trauma Rehabilitation, 2014; 29(4), pp. 353-368.

62. Wiseman-Hakes SC, Ryu H, Lightfoot D, Kukreja G, Colantonio A and Matheson FI 'Examining the Efficacy of Communication Partner Training for Improving Communication Interactions and Outcomes for Individuals With Traumatic Brain Injury: A Systematic Review', Archives of Rehabilitation Research and Clinical Translation, 2020; 2(1), pp. 100036.

63. Behn N, Francis J, Togher L, Hatch E, Moss B, \& Hilari K. Description and Effectiveness of Communication Partner Training in TBI: A Systematic Review. The journal of head trauma rehabilitation, 2020 Publish Ahead of Print. doi:10.1097/HTR.0000000000000580

64. Togher L, Power E, Rietdijk R, McDonald S, Tate R. An exploration of participant experience of a communication training program for people with traumatic brain injury and their communication partners. Disability and Rehabilitation, 2012;34(18): 1562-1574. https://doi.org/10.3109/09638288.2012.656788

65. Grayson L, Brady MC, Togher L, Ali M. A survey of cognitive-communication difficulties following TBI: are families receiving the training and support they need? 
International journal of language \& communication disorders, 2020. doi:10.1111/1460-6984.12555

66. Russell WR, Smith A, Post-Traumatic Amnesia in Closed Head Injury. Archives of Neurology, 1961;5(1):4-17. https://doi.org/10.1001/archneur.1961.00450130006002

67. Braun V, Clarke V. Using thematic analysis in psychology. Qualitative Research in Psychology,2006;3(2):77-101.https://doi.org/10.1191/1478088706qp063oa

68. Tong A, Sainsbury P, Craig, J. Consolidated criteria for reporting qualitative research (COREQ): a 32-item checklist for interviews and focus groups. Int Journal for Quality in Health Care, 2007;19(6):349-357. https://doi.org/10.1093/intqhc/mzm042

69. Plosker R, Chang JA. Solution- Focused Therapy Group Designed for Caregivers of Stroke Survivors. Journal of Systemic Therapies, 2014;33(2):35-49. https://doi.org/10.1521/jsyt.2014.33.2.35 
Table 1: Themes, Categories and subcategories:

\begin{tabular}{|c|c|c|}
\hline Themes $(n=3)$ & Categories $(n=9)$ & Subcategories $(n=35)$ \\
\hline \multirow[t]{2}{*}{ Family Experience of CCD } & Difficulties experienced & $\begin{array}{l}\text { Emotions/empathy } \\
\text { "Filter switch" } \\
\text { Flexibility and difficulty } \\
\text { accepting feedback } \\
\text { Insight } \\
\text { Memory } \\
\text { Initiation } \\
\text { Word finding/verbosity }\end{array}$ \\
\hline & Strategies & $\begin{array}{l}\text { Structure and support } \\
\text { Clear expectations } \\
\text { Time } \\
\text { Self-care/respite }\end{array}$ \\
\hline \multirow[t]{4}{*}{ Impact of CCD on family } & Emotions & $\begin{array}{l}\text { Anxiety/need to tread carefully } \\
\text { Guilt/ "Being the bad guy" } \\
\text { Exhaustion } \\
\text { Added Responsibility } \\
\text { Isolation/ feeling alone } \\
\text { Anger/frustration }\end{array}$ \\
\hline & Perception of others & $\begin{array}{l}\text { Hidden disability } \\
\text { Misperception of wider network } \\
\text { Within family differences }\end{array}$ \\
\hline & Change to relationships & $\begin{array}{l}\text { Role changes } \\
\text { Reduced collaboration } \\
\text { Relationship type differences }\end{array}$ \\
\hline & Change to social activities & $\begin{array}{l}\text { Avoidance } \\
\text { Reduced independence } \\
\text { Reduced social contacts }\end{array}$ \\
\hline \multirow[t]{3}{*}{ How services can support } & Information & $\begin{array}{l}\text { Format and content } \\
\text { Timing } \\
\text { Signposting }\end{array}$ \\
\hline & Training & $\begin{array}{l}\text { Perception of training } \\
\text { Format/content } \\
\text { Timing }\end{array}$ \\
\hline & Support & $\begin{array}{l}\text { Format/content } \\
\text { Timing } \\
\text { Signposting }\end{array}$ \\
\hline
\end{tabular}


Table 2: Family experience of cognitive-communication difficulties

\begin{tabular}{|c|c|c|}
\hline Subcategory & Groups/comments & Illustrative Quotes \\
\hline \multirow[t]{3}{*}{$\begin{array}{l}\text { Recognising the } \\
\text { emotional needs of } \\
\text { others }\end{array}$} & $\begin{array}{c}4 / 4 \\
n=32\end{array}$ & $\begin{array}{l}\text { Can't see when the other person is offended or } \\
\text { bored or needs to leave. Just doesn't see it. Can't see } \\
\text { those emotions (P1, } 0-12 \mathrm{~m})\end{array}$ \\
\hline & & $\begin{array}{l}\text { It's all about how he's feeling which I find very } \\
\text { difficult because sometimes I think it would nice if } \\
\text { he could give me a hug and ask me how I'm feeling } \\
\text { but that doesn't happen (P5, 12-36m) }\end{array}$ \\
\hline & & $\begin{array}{l}\text { He's very self-involved. He really does just think } \\
\text { about where he's going, what's happening to him. } \\
\text { He doesn't really think about me or take other } \\
\text { people into consideration (P9, } 36 \mathrm{~m}+\text { ) }\end{array}$ \\
\hline \multirow[t]{2}{*}{$\begin{array}{l}\text { Accepting feedback } \\
\text { and being flexible }\end{array}$} & $\begin{array}{c}4 / 4 \\
n=31\end{array}$ & $\begin{array}{l}\text { He's been trying to ring me since I came in, but he } \\
\text { just cannot, if he needs something, and I'm like is it } \\
\text { something that can wait because I'm in a meeting, } \\
\text { but he can't wait (P3, } 0-12 \mathrm{~m} \text { ) }\end{array}$ \\
\hline & & $\begin{array}{l}\text { Because sometimes he'll just go away. Maybe I } \\
\text { have disagreed with what he's said. He's come in } \\
\text { from work and he said such and such and I said, } \\
\text { well, that maybe wasn't the right way and it ends up } \\
\text { he spends the night in the other room (P5, 12-36m) }\end{array}$ \\
\hline "Filter switch" & $\begin{array}{c}4 / 4 \\
n=28\end{array}$ & $\begin{array}{l}\text { But to him he's correct he says I'm honest. He's } \\
\text { right but he's very, unfiltered. To him, it's a joke but } \\
\text { to other people, it's offensive (P2, } 0-12 \mathrm{~m})\end{array}$ \\
\hline
\end{tabular}

And the swearing! That's terrible now (P6, 12-36m)

Knowing what is appropriate to say to what kind of people because he can be really open now. You don't need to go into so much detail, that can just stay between us (P12, 36m+)

Impact of tolerance levels and fatigue on CCD

Reduced insight into CCD on CCD

Reduced initiation of interactions $\mathrm{n}=12$
By the time it gets to Wednesday he gets exhausted so he doesn't even have any social skills with me never mind anyone else (P5, 12-36m)

I'd say that his temper is much shorter now than it used to be so he can sometimes get very frustrated in conversations over something that I would deem to be the tiniest of issues $(\mathrm{P} 10,36 \mathrm{~m}+)$

But the problem was he had no awareness so I would be saying to the therapist this is happening and he would be going no it's not (P1, 0-12m)

I think he thinks that he's much better than he is and he thinks he's much more capable than he is on the phone, when talking (P9, 36m+)

He repeats himself. Whatever the topic is that day $(\mathrm{P} 15,36 \mathrm{~m}+)$

She's still not got into phoning up her friends so I have to say go and phone, go phone (P8,12-36m) 
L. GRAYSON ET AL

Word Finding/

Verbosity

$2 / 4$

$\mathrm{n}=3$
It's more word-finding. He'll say something then go nope and take a wee while to find the word he is looking for (P7, 12-36m)

He has to provide every little detail from start to finish. You try to break in but it's impossible you just can't stop him (P14, 36m+)

Key: $\mathrm{P}=$ participant/family member; $\mathrm{n}=* *$ 
L. GRAYSON ET AL

Table 3: Family Strategies for supporting Cognitive-Communication Difficulties

Strategy subthemes

Structure and Support

Clear expectations

Timing of feedback

Self-care and respite

\section{Illustrative Quotes}

We really need to make sure that somebody's with him to support him....as he'll come back and tell you things. And it's not accurate either (P2, 0-12m)

I always have to watch the faces of the people he is talking to. To find out if I need to intervene. Can't ever relax $(\mathrm{P} 13,36 \mathrm{~m}+)$

I am very straight with him. I do say to him, I try my best to make him aware (P4, 0-12m)

I have to sometimes remind him who we're going out with and what things would be appropriate to say to people and what wouldn't be appropriate because he is very honest now $\left(\mathrm{P9}, 36 \mathrm{~m}^{+}\right)$

Sometimes, you just have to let it go, because he can't see it $(\mathrm{P} 3,0-12 \mathrm{~m})$

Not trying to have that conversation at $10 \mathrm{pm}$ when he is exhausted (P8, 12-36m)

He goes in a huff with me, so I just ignore him, for a wee while. He obviously sits there and thinks about it and then he comes back around (P14, 36m+)

He's stays with me, but he goes to his partner's sometimes and that's been a godsend, because I think if he was 24/7, I would have... I don't know how I would have coped (P1, 0-12m)

He cannot see my perspective in anything and it's so frustrating to constantly back down and just go, okay. Sometimes I just need to take the time and I'll go to the gym because I need to get out of there, before I end up saying something that I'll regret $(\mathrm{P9}, 36 \mathrm{~m}+)$

Key: $\mathrm{P}=$ participant/family member; $\mathrm{n}=* *$ 
Table 4: Emotional impact of Cognitive-Communication Difficulties on the family

Emotional Impact of CCD

Feel like "the bad guy"

Need to tread carefully

Always feel responsible

Frustration and anger

Guilt

Sadness

Loneliness

Isolation

Exhaustion

Within family differences

Perception of wider family, friends and strangers

\section{Illustrative Quotes}

I feel like a punching bag. I feel as if he's just, you know bang, bang. It's nothing physical, but it's just, it always has to be his way” (P3, 0-12m)

"I do feel like I'm the bad guy all the time and I feel quite on my own because nobody helps me with that" $(\mathrm{P} 9,36 \mathrm{~m}+)$

"It can be exhausting just to try and think not just for yourself but for someone else" (P13, 36m+)

I'm working with what's wrong with him, I can accept it but my husband and his brother, they're in denial. Their way of coping is, he's putting that on. My husband, knows but he doesn't want to see it. It's easier to say he's at it (P1, 0-12m)

Sometimes it's worse though if it's not obvious. Do you ever find that? Because you feel you are constantly apologising to people” (P14, 36m+)

Key: $\mathrm{P}=$ participant/family member; $\mathrm{n}=* *$ 
Table 5: Impact of Cognitive-Communication Difficulties on Relationships

\section{Relationships}

Changes to roles

Relationship type differences

Reduced Collaboration

\section{Illustrative Quotes}

But when you're talking about the relationship with him, we're very close but we don't talk like husband and wife any more, it's more like I'm his pal (P5, 12-36m)

He is friends with the kids which is obviously great but there isn't that fatherly thing so I do all that now (P12, 36m+)

My son doesn't pick up the guitar because Dad's not doing it with him anymore. Because that was their thing. They would chat and play together (P1, 0-12m)

I think it's easier in our case where it was our son. It was your husband and your wife, so you can't talk to them about it, whereas my wife and I can sit and discuss it (P6, 12-36m)

I think the relationship's different, because it's not my husband, it's my son. And I think if it was my husband, I'd probably be less tolerant (P2, 0-12m)

It's different for us as we can say "goodnight" and walk away at the end of the day whereas you (the spouse) are there round the clock $(\mathrm{P} 10,36 \mathrm{~m}+)$

She phoned the police on me because she thought I wouldn't let her go up to see her brother. We used to be such a good team $(\mathrm{P} 7,12-36 \mathrm{~m})$

What the brain injury team said was gospel. He believed what you were saying, but not so much me, I was talking rubbish. I couldn't help (P5, 12-36m)

I could see what the therapist was trying to do so I'd say try this. But she flies off the handle and won't take any advice from me because what do I know about it (P11, 36m+)

Key: $\mathrm{P}=$ participant/family member; $\mathrm{n}=* *$ 
L. GRAYSON ET AL

Table 6: Impact of Cognitive-Communication Difficulties on Social Participation

Social Participation

Difficulty initiating social contact

\section{Illustrative Quotes}

But meeting people, she's still not got into phoning up her friends or going out to see them either (P7, 12-36m)

He doesn't really want to engage in conversation with anybody so you can imagine come Friday, when I'm trying to get him to meet up with other people, it doesn't work (P5, $12-36 \mathrm{~m})$

Diminishing social circles

No, he doesn't go out a lot. He's got one friend in particular who he hangs about with and his young cousin. That's about it $(\mathrm{P9}, 36 \mathrm{~m}+)$

Key: $\mathrm{P}=$ participant/family member; $\mathrm{n}=* *$ 
Table 7: Optimizing information about Cognitive-Communication Difficulties for families

Information

Illustrative Quotes

1:1 I think if you could get an appointment when they're not there. You can say more, your point of view without upsetting them as they have no awareness of what is wrong (P4, 0-12m)

Own family Just our family not a group. I know it's very selfish but the situation you're in is yours alone and you want to know how to deal with it (P6, 12-36m)

Specific To be able to say to me this is where he was injured and this is why he's acting like information that. Because I just thought he was being a difficult pain in the backside (P5, 12-36m)

To show me which part of the brain is making her do this so you know where it's all coming from (P8, 12-36m)

Written I think a brain injury pack with information is essential. At the beginning you have no information time to read or take anything in but when you are at home at least you would have that pack to turn to $(\mathrm{P} 13,36 \mathrm{~m}+)$

Timing You need it straight away and further down the line as you can't take it all in at once Its only later you begin to see those other things like personality and emotions and by then there's no one to ask (P1, 0-12m)

Key: $\mathrm{P}=$ participant/family member; $\mathrm{n}=* *$ 
L. GRAYSON ET AL

Table 8: Family perception of the need for Communication Partner Training

Training

For

Timing

Against It's just that maybe you wouldn't agree with what they were saying, at this point you

\section{Illustrative quotes}

I think someone telling you what you are not doing right and showing you how to do it better would have been good. You are trying to tell other people what to do and you don't even know yourself. It would be good to say this is what the experts are saying this is the right way $(\mathrm{P} 12,36 \mathrm{~m}+)$ should be doing that. I would go, well, maybe you're right, but I'm doing this to get through the day (P4, 0-12m)

I think you should go with the flow yourself. Because you know that person and you know what you can say to him and what you can't (P2, 0-12m)

You really needed to find out what you were up against first then see what training you need because you just don’t know in those first weeks and months (P7, 12-36m)

Key: $\mathrm{P}=$ participant/family member; $\mathrm{n}=* *$ 
L. GRAYSON ET AL

Table 9: Optimising Family Support for Cognitive-Communication difficulties

\section{Support}

\section{Illustrative Quotes}

Peer support Because we're nodding at each other and talking and that really helps me. It makes me think it isn't just me, it's not in my head (P1, 0-12m)

When these two ladies were describing their sons, it's like, I'm not making this up. At last, I've got somebody to speak to (P4, 0-12m)

I love the thought of helping somebody else because I know how horrendous I felt right at the beginning. $(\mathrm{P} 9,36 \mathrm{~m}+)$

Timing Further down the line because initially all you're doing is going to the hospital then when she comes out it's looking after everything. Ironing, washing, taking her to the toilet. You can't think about you (P7, 12-36m)

Signposting I'd have actually quite liked to have seen my husband be offered counselling and then maybe an opportunity for us to come together and address it as a couple (P5, 12-36m)

Key: $\mathrm{P}=$ participant/family member; $\mathrm{n}=* *$ 